Nat. Hazards Earth Syst. Sci., 17, 2109-2123, 2017

https://doi.org/10.5194/nhess-17-2109-2017

(C) Author(s) 2017. This work is distributed under

the Creative Commons Attribution 4.0 License.

\title{
Flood impacts on a water distribution network
}

\author{
Chiara Arrighi $^{1}$, Fabio Tarani ${ }^{2}$, Enrico Vicario $^{2}$, and Fabio Castelli ${ }^{1}$ \\ ${ }^{1}$ Università di Firenze, DICEA, Department of Civil and Environmental Engineering, Firenze, Italy \\ ${ }^{2}$ Università di Firenze, DINFO, Department of Information Engineering, Firenze, Italy
}

Correspondence to: Chiara Arrighi (chiara.arrighi@dicea.unifi.it)

Received: 7 June 2017 - Discussion started: 19 June 2017

Revised: 25 September 2017 - Accepted: 25 October 2017 - Published: 1 December 2017

\begin{abstract}
Floods cause damage to people, buildings and infrastructures. Water distribution systems are particularly exposed, since water treatment plants are often located next to the rivers. Failure of the system leads to both direct losses, for instance damage to equipment and pipework contamination, and indirect impact, since it may lead to service disruption and thus affect populations far from the event through the functional dependencies of the network. In this work, we present an analysis of direct and indirect damages on a drinking water supply system, considering the hazard of riverine flooding as well as the exposure and vulnerability of active system components. The method is based on interweaving, through a semi-automated GIS procedure, a flood model and an EPANET-based pipe network model with a pressuredriven demand approach, which is needed when modelling water distribution networks in highly off-design conditions. Impact measures are defined and estimated so as to quantify service outage and potential pipe contamination. The method is applied to the water supply system of the city of Florence, Italy, serving approximately 380000 inhabitants. The evaluation of flood impact on the water distribution network is carried out for different events with assigned recurrence intervals. Vulnerable elements exposed to the flood are identified and analysed in order to estimate their residual functionality and to simulate failure scenarios. Results show that in the worst failure scenario (no residual functionality of the lifting station and a 500-year flood), $420 \mathrm{~km}$ of pipework would require disinfection with an estimated cost of EUR 21 million, which is about $0.5 \%$ of the direct flood losses evaluated for buildings and contents. Moreover, if flood impacts on the water distribution network are considered, the population affected by the flood is up to 3 times the population directly flooded.
\end{abstract}

\section{Introduction}

Extreme weather events and major natural disasters are listed in the top five global risks in terms of likelihood and impact (World Economic Forum, 2017). Climate change perspectives (IPCC, 2013; Lung et al., 2013) raise additional concerns about floods due to their consequences on population (Ashley and Ashley, 2008), environment (Christodoulou, 2011), urban areas and infrastructures (Meyer et al., 2013; Emanuelsson et al., 2014; Khan et al., 2015; Short et al., 2012). This leads to an increasing interest in studying flood impacts, as shown, for instance, by the sustainability criteria adopted for flood risk mitigation strategies in EU countries (EU Parliament, 2007), which promotes quantitative flood risk assessment (Merz et al., 2010) and flood damage maps (de Moel et al., 2009; Meyer et al., 2013).

Flood damage to structures and infrastructures is classified into direct and indirect, the former being caused by physical contact with floodwater and the latter occurring far from the event in either space or time (Thieken et al., 2006). On the one hand, direct losses to private dwellings, household contents and economic activities can be estimated through damage curves, which relate water depth to relative losses (Smith, 1994); on the other hand, interdependence of assets in network infrastructures induces impacts outside the flooded areas, sometimes with substantial effects (Gil and Steinbach, 2008). Hence, the assessment of flood impact on networks partially in direct contact with water requires the evaluation of the repercussions on the overall system behaviour. As a matter of fact, failure of crucial infrastructures may lead to cascade events and trigger technological disasters (Cruz et al., 2004). Cascading events are more likely to occur during a natural disaster than during normal plant operation because of the increased chance of multiple, simul- 
taneous failures. While flood damage evaluation to buildings and their contents is becoming increasingly available (Merz et al., 2010), the quantification of direct and indirect impacts on critical infrastructures is less common (Lhomme et al., 2013; Michielsen et al., 2016; Emanuelsson et al., 2014).

The assessment of flood risk requires the evaluation of the three risk components - i.e. hazard, vulnerability and exposure - for each subsystem and the assessment of functional dependencies (Serre et al., 2011). In particular, flood hazard of a component relates to the likelihood of being flooded, which can be evaluated through flood maps; exposure is the position with respect to inundation extent and vulnerability is the proneness to being harmed (Meyer and Messner, 2005). Vulnerability of a network can be intended as the susceptibility of a single network portion or device as well as the fragility of the whole system in relation to the failure of a system component. This distinction is particularly crucial for network infrastructures where the failure of one node may trigger harmful effects even very far from the affected area, leading to indirect damage.

Among safety critical infrastructures are freshwater supply systems (WSSs; see Table A1 for a list of acronyms used in the paper) and water treatment plants, which can be severely affected by floods since they rely on electric power, mechanic devices and electronics. Water supply and sanitation is widely considered to be a main factor in environmental sustainability, human health, social services and resilience (WHO, 2011; Luh et al., 2017). In particular, water distribution networks (WDNs) are complex systems composed by a number of subsystems in charge of abstraction from the source, transportation, treatment and distribution. Vulnerable WSS components are often located in low-lying areas or nearby rivers, with a consequent high exposure to inundations. Flood events affecting water utilities can lead to costly repairs, disruptions of service and public health advisories (US Environmental Protection Agency, 2014).

The management of flood risk entails a combined approach comprising mitigation, preparedness, response and recovery (WHO, 2011). Among the mitigation activities, the identification of hazard and a comprehensive vulnerability analysis are recognised as pre-eminent. Risk assessment is a fundamental support for decision makers because it increases the awareness and fosters the adoption of mitigation strategies (Large et al., 2014). The implementation of the Water Safety Plan promoted by the World Health Organization (WHO) and International Water Association (IWA) (Bartram et al., 2009) aims to harmonise hazard and risk assessment procedures through an appropriate method. It identifies issues of treatment plants and source water quality (Ginandjar et al., 2015) as the main hazards associated with floods. Floods and heavy rainfall are associated with elevated turbidity and dissolved organic matter (Göransson et al., 2013; Murshed et al., 2014), which can affect drinking water purification, the source of which is a surface water body or storage reservoir. However, if indirect and cascade effects are accounted for, other impacts should be considered such as those related to power outage, which is likely to occur if electric devices, e.g. valves and lifting stations, are affected (Khan et al., 2015). In fact, a short-term loss of the electric power may induce pressure fluctuations or intermittent supply, which may lead to ingress of contamination from leakage orifices and air vacuum valves (Ebacher et al., 2010). Thus, besides the economic costs caused by the contamination, of the order of EUR 50 per metre of cleaned pipe (Ellison et al., 2003), there are repercussions on social and operational domains characterising urban water systems (Blackmore and Plant, 2008; Hrudey et al., 2006). Hence, a comprehensive flood risk assessment of WSSs should integrate a flood model and a WSS model capable of properly representing the network behaviour in low-pressure conditions (Seyoum and Tanyimboh, 2016).

In this work, a method is implemented as to evaluate flood impact on a WSS accounting for both direct and indirect damage on technological systems and inhabitants. Hazard, vulnerability and exposure of system components are assessed through a semi-automated procedure integrating the geographic information system (GIS) representation of flood scenarios with an hydraulic network model with pressuredriven demand (PDD). Failure scenarios are based on the analysis of exposure and vulnerability of critical network components, e.g. lifting stations. Two measures for the assessment of flood impact are introduced and the model is tested on a case study.

\section{Materials and methods}

The assessment of flood risk on a WSS requires a comprehensive approach including several scales of analysis (e.g. catchment area, riverbed, distribution network) and models in order to capture the dependencies between environmental forcing and WSS components and the inner dependencies of the WSS itself. Figure 1 depicts the logic flow to estimate flood impacts on each component of the WSS considering a configuration with a surface water body source, e.g. a river. Reading the scheme clockwise, at catchment scale the hydro-meteorological event ( 1 on the diagram) bears turbidity, due to the high concentration of suspended sediments, and organic matter load, both of which affect the surface water body (2). When reaching the abstraction, the quality of source water needs to be analysed (3) to determine whether the influent (i) is suitable for a standard treatment, (ii) requires adjustments of the treatment process or (iii) is not appropriate, leading to a temporary interruption of abstraction (4). Uncontrolled or special source water quality may directly affect the treatment with possible failures of the process sections and consequences on treatment efficiency $(5,6)$. Treatment plants are also susceptible to failure or restrictions if vulnerable active components are flooded. Active components (7) are those powered by electricity such 
Table 1. Main impacts associated with flooding for WSS based on surface water source.

\begin{tabular}{|c|c|c|}
\hline WSS component & Direct flood impact & Consequence \\
\hline \multirow{2}{*}{ Abstraction } & Turbidity & Abstraction interruption \\
\hline & Organic matter load & Restriction of treatment \\
\hline \multirow{3}{*}{ Treatment } & Power shutdown & Loss or restriction of treatment works \\
\hline & Instrumentation failure & Loss of control \\
\hline & Drinking water contact with floodwater & Contamination \\
\hline \multirow{3}{*}{ Distribution } & Power shutdown & Pressure fluctuations \\
\hline & & Intermittent supply \\
\hline & & Contamination \\
\hline
\end{tabular}

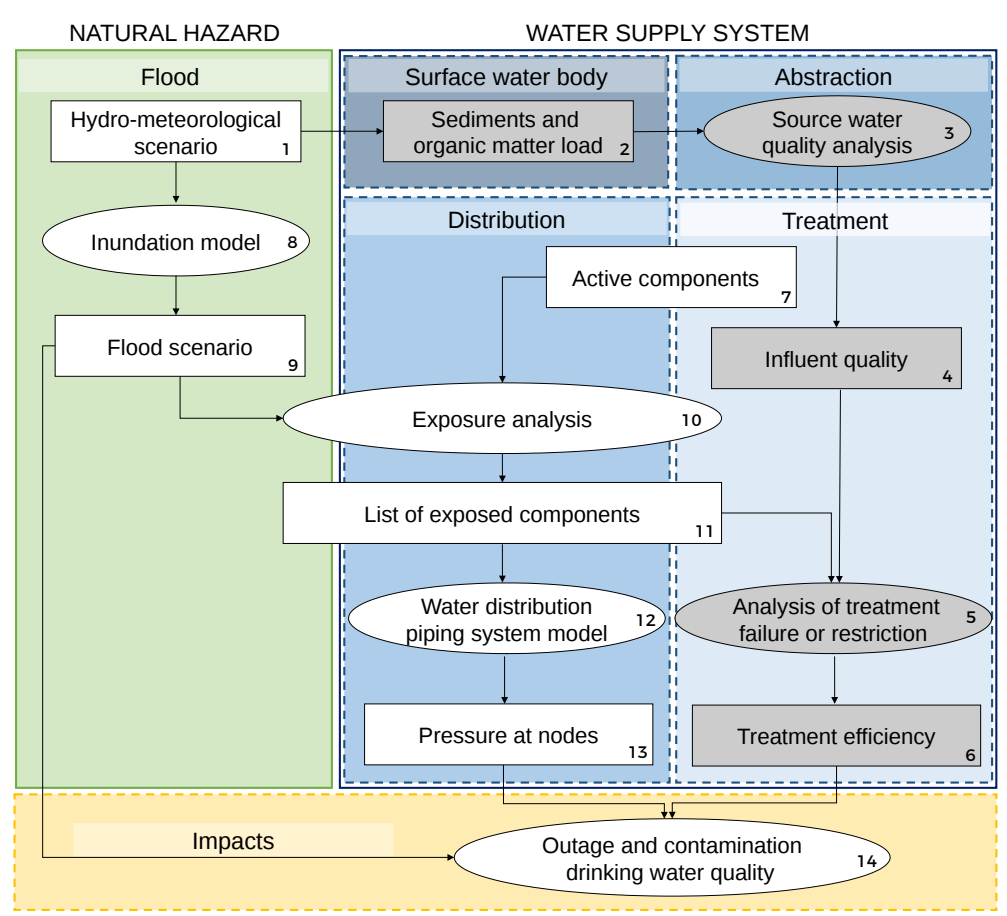

Figure 1. Flood risk assessment scheme for WSS (ellipses stand for activities and rectangles represent data flow; shaded boxes represent activities that are not carried out in this work).

as electric valves, pumps, chemical dosers, etc. The WDN, which relies on elements sensitive to power outage (e.g. lifting stations), is also affected. The inundation model (8) generates a flood scenario (9), i.e. an inundation map which allows one to identify exposed objects. Exposure analysis (10) produces a list of exposed components (11) for both WDN and treatment, the possible failure of which should be simulated in a piping distribution system and a treatment plant models, respectively (12). Therefore, the results of the models in terms of pressure at nodes (13) and treatment efficiency are used to estimate the impacts on water quantity (outages due to pressure fluctuations or intermittent supply) and quality, e.g. the risk of contamination (14). The main effects of flood impacts are summarised in Table 1.
This work focuses on the evaluation through a numerical model of flood impacts on the WDN, shown in the central panel of Fig. 1. The model is composed by two main submodels: the inundation model and the WSS model.

\subsection{Inundation model and exposure analysis}

The inundation model uses a river hydrograph (either recorded or calculated for a hydro-meteorological scenario) to produce a raster map showing the representative flood parameters, in particular water depth. In the literature computation is commonly performed through simplified NavierStokes equations with different numerical schemes and spatial resolutions of the computational domain (Hunter et al., 2008). In particular, accurate forecast of flood propagation 
in urban environments usually requires 2-D models with an adequate description of the street-building pattern, limiting the computational grid resolution to about $1 \mathrm{~m}$ (Apel et al., 2009). In this context, the increasing availability of geographic data such as lidar-derived digital terrain models (DTMs) ease the setup of the model (Fewtrell et al., 2011). Nevertheless, some issues such as the computational effort and the definition of representative roughness coefficients still arise. As an alternative, parsimonious hydraulic models are also accepted as a compromise between accuracy and computational effort when steady-state approximations and large and cumbersome computational domains are not sustainable (Apel et al., 2009; Arrighi et al., 2013).

The implemented hydraulic model is comprised of two parts. Firstly, the river is represented with a 1-D unsteady flow model and the urban flood-prone area is modelled as a system of interconnected quasi-2-D storage cells. A digital surface model with resolution of $1 \mathrm{~m}$ and vertical accuracy of $0.25 \mathrm{~m}$, derived from lidar surveys, is used for the detailed representation of the flow domain at street-building scale; buildings are, by default, considered to be waterproof blocks. The computation of flood propagation is performed through an implicit 1-D finite-difference scheme of the general equation of unsteady flow (i.e. mass and momentum conservation equations). The quasi-2-D hydraulic model for the floodplain consists of several storage areas (cells) connected to the riverbanks through a set of lateral weirs, whose geometry is extracted from a topographic survey. When the inundation starts, the quasi-2-D module - governed by mass conservation and stage-storage relationships - calculates water levels from the volume stored in the cell. Flow between adjacent cells is described by a weir equation accounting for backwater effects. The details of the model construct and equations adopted in the HEC-RAS framework (for both 1-D and quasi-2-D modules) are described in Arrighi et al. (2013). The increasing availability inundation maps from local water authorities - due to the evolving normative frameworks in flood risk management (EU Parliament, 2007) - may also offer an alternative to numerically simulating surface flow. In this perspective, official inundation maps can be adopted if accessible and adequate in spatial resolution in the area of interest.

Exposure analysis requires matching of data from inundation maps and information on location of assets, usually performed by means of GIS. All the components of the WDN, both active and passive, must therefore be geo-referenced to be compared with inundation maps for assigned scenarios. For the risk assessment of the WDS, exposure analysis is conducted on active components based on the maximum water depth occurring during the flood event. Maximum water depth is also used to assess the potential contamination at nodes. The selection of a suitable inundation model giving accurate flood depths depends on the characteristics of the domain, i.e. area and topography, although a spatial resolution of the order of $1 \mathrm{~m}$ (e.g. lidar-derived products) should be preferred in urban areas to represent the street-building pattern. Exposure analysis consists of four steps. First, the coordinates of the WSS point components (nodes, reservoirs, lifting stations, etc.) are exported from the WSS model to the GIS environment so that a new vector is created whose coordinate reference system is assigned in the shapefile properties. Afterwards, the raster inundation map is imported into the GIS workspace and converted if necessary to a compatible reference system. The raster cell information (i.e. water depth) is then extracted over the point feature and added as attribute (e.g. with the "point sampling tool" plug-in available for QGIS). For each failure-prone point component belonging to an exposed asset, the water depth attribute is compared to a threshold depth which takes into account local geometry and functional dependencies. If calculated depth exceeds the threshold, the component is marked as failed, added to the list of exposed asset and its properties modified in the WSS model (Sect. 2.2) to reproduce the failed configuration.

\subsection{Distribution network model}

The model is based on the freely available EPANET libraries, which calculate time-varying pressures at the nodes given a set of initial tank levels, pump switching criteria, base nodal demands and demand patterns. In particular, EPANET can be launched by other software through a set of DLL libraries.

One drawback of the standard EPANET implementation is its strict demand-driven approach, which stems from the primary goal of simulating correctly operated networks. In such networks, pressure at each node is sufficient so as to allow withdrawal of required flow rate from each node, so that demands can be assumed as defined input data. However, when simulating strongly off-design networks, nodes featuring a reduced pressure are quite common, so that a PDD approach is needed (Cheung et al., 2005; Walski et al., 2017). PDD models differ from conventional ones in that nodal demands are not attributed a priori; instead, their value depends on the current local pressure. In particular, and consistently with practice, the model assumes that each node is in one of three states:

- Fully served: if $H_{i} \geq H_{\text {service, }}$, the node is able to withdraw its nominal demand.

- Partially served: if $H_{\text {service }}>H_{i}>0$, the node withdraws a reduced demand, which can be expressed as

$$
D_{i}=D_{\text {nom }, i}\left(\frac{H_{i}}{H_{\text {service }}}\right)^{\alpha} \text {, }
$$

where $\alpha$ is a constant exponent set to 0.5 .

- Non-served: if $P=0$, the node is unable to withdraw any water, yielding null demand.

EPANET allows two types of nodes: nodes are assigned a time-varying, pressure-independent demand and can be effectively used to model fully served users, whereas emitters, 
conceived to model fixed cross-section water outlets such as fire hoses and orifices, adequately model the aforementioned behaviour of partially served users. Emitters are defined by a fixed exponent $\alpha$, equal for all instances, and a flow coefficient which represents the volume flow rate for unitary pressure loss across the orifice. Unfortunately, emitters do not cope well with calculated negative pressures, attributing a negative (entering) flow rate where such negative pressures occur. In order to cope with this issue, a MATLAB code has been implemented so as to run transient simulation while correctly using a PDD approach. The code, as shown in Fig. 2, works as follows. Three node states are defined: "2" for served nodes, " 1 " for partially served ones and "0" for non-served ones; type 2 and type 0 nodes are modelled as EPANET nodes with nominal demand equal to the assigned nominal demand $D_{i}$ and nought, respectively, whereas type 1 nodes are modelled as emitters whose flow coefficients are calculated to ensure that $D_{i}=D_{\text {nom, }, i}$ if $H_{i}=H_{\text {service }}$.

Overall, the model works as follows: for each time step, a first trial simulation is run with all nodes in state 2 in order to get the expected pressures. Afterwards, each node is checked to assess whether its pressure is in the pressure range corresponding to the current flow regimen and, if this is not the case, its state is accordingly raised or lowered by one unit (namely, it is not possible to jump from state 2 to state 0 and vice versa). After node states have been changed, simulation is repeated until no more state change is necessary. Calculated flow rates and pressures are considered to represent network operation during the subsequent time step. In particular, flow rates are used to calculate the time to the next event (tank being filled or drained), and the first event affecting network topology is considered (e.g. demand change, pump setting toggling due to time pattern, tank becoming empty or full). Tank levels are thus updated and simulation proceeds to the next time step. The described procedure allows for calculating pressure and supplied demand at each node for each time step, therefore fully estimating the network state in each moment.

\section{Model initialisation}

The model, featuring non-memoryless elements (tanks), needs to be correctly initialised. In normal operation, tank levels undergo a daily pattern of filling and emptying, according to demands and water availability. In order to appropriately initialise tank levels, a warm-up simulation is run by randomly initialising tank levels and checking their value every $24 \mathrm{~h}$. If the calculated levels differ from those corresponding to $24 \mathrm{~h}$ before by less than a tolerance parameter, the model is considered to be in steady state and water level for each tank and time value are saved in a matrix, which can thereafter be used to initialise the values for the forthcoming simulations.

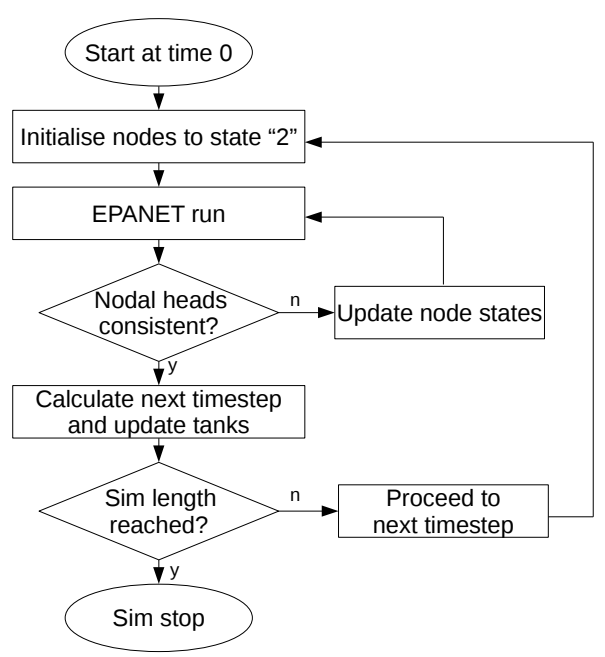

Figure 2. Diagram of PDD model implementation.

\subsection{Definition of impact measures}

Two measures have been defined in order to evaluate the global impact of the flood on network operativeness and integrity.

First, impact of the flood on network operation is assessed through evaluation of the number of inhabitants experiencing lack of service. To this aim, data about population density in the area made available by the Italian Institute of Statistics (ISTAT, 2011) are used. Such data define 2186 polygonal zones with areas ranging from 156 to $2.48 \times 10^{6} \mathrm{~m}^{2}$ ) and provide a population value for each of them. Inhabitants are assigned to nodes as follows: a uniform demand per capita is assumed in each area and calculated, and the number of inhabitants for each node pertaining to that area is estimated accordingly. In particular,

$P_{i \in A}=\frac{D_{\text {nom }, i}}{\sum_{k \in A} D_{\text {nom }, k}} P_{A}$,

where $P_{i}$ is the population assigned to node $i$ belonging to area $A$ and $P_{A}$ is the total population of area $A$. The population not served, $\left(P_{\mathrm{NS}}\right)$, parameter is thus estimated as the total population of nodes with reduced or null pressure, i.e.

$P_{\mathrm{NS}}=\sum_{i \in I} P_{i}$ with $I=\left\{i \mid H_{i}<H_{\text {service }}\right\}$,

where $H_{\text {service }}$ is the minimum head required to consider a node fully served (5.0 $\mathrm{m}$ in the case study).

As a second measure, network damage due to pipe contamination is evaluated by calculating the total length of pipework to be decontaminated. A pipe is considered to be contaminated if at any point in time the head inside the pipe is lower than the floodwater head outside or below zero, i.e. 


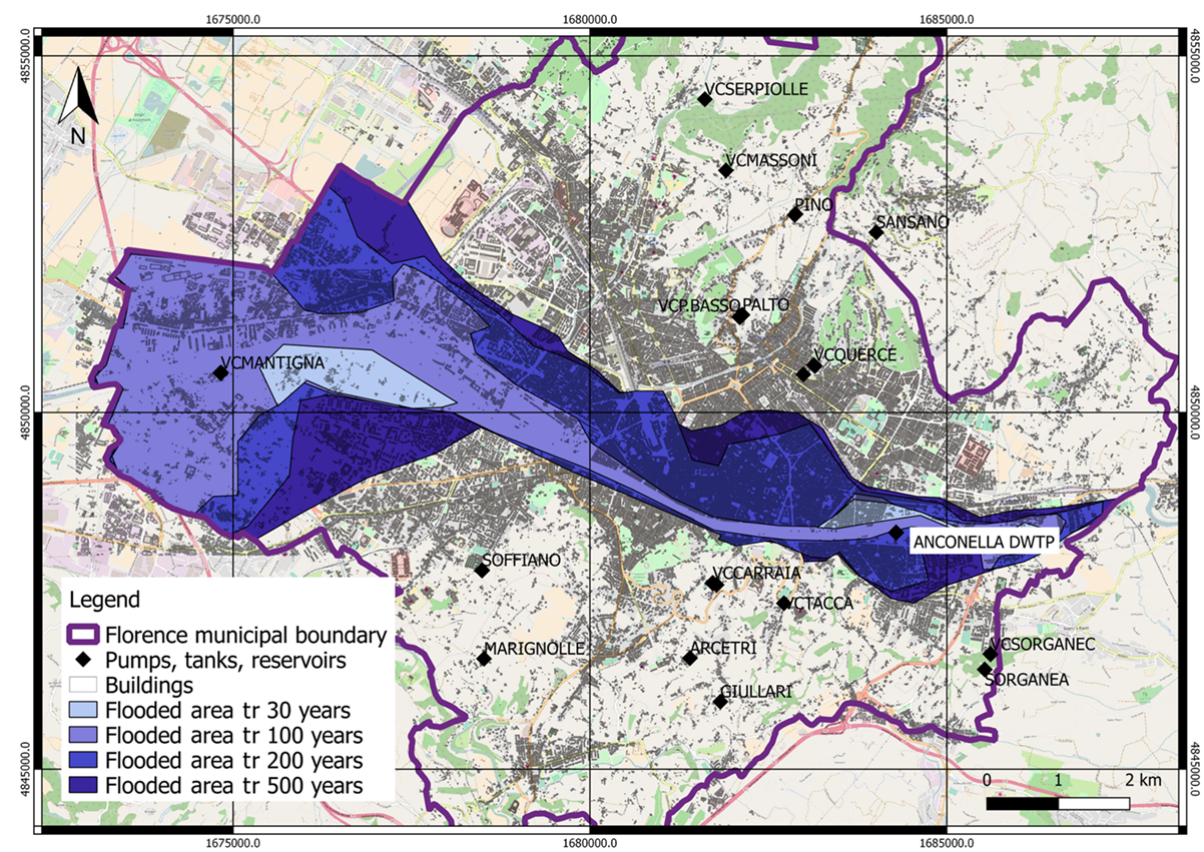

Figure 3. Flooded area for the four recurrence intervals and exposure of vulnerable components. Areas with water depth above $0.01 \mathrm{~m}$ are considered to be flooded). Reference coordinate system is EPSG:3003.

$L=\sum_{i \in I} \sum_{j \in J_{i}} L_{j}$ with $I=\left\{i \mid H_{i}<\max \left(H_{\text {flood }}, 0\right)\right\}$

where $J_{i}$ is the set of pipes with either end connected to node $i$.

\section{Case study}

\subsection{Flood scenarios}

The study area is the municipality of Florence, Italy, with an areal extent of $102 \mathrm{~km}^{2}$. The area hosts about $380000 \mathrm{in}-$ habitants, the highest population density being found in the city centre along the Arno riverbanks. Documents indicate that the town has a long account of floods since the Middle Ages, as confirmed by more recent hydrologic-hydraulic studies (Caporali et al., 2005) showing that floods may occur also for low recurrence interval (30-year return period). For such frequent events, only the lower-lying suburbs are affected (brown areas on the centre left side of Fig. 8), whereas more severe scenarios (recurrence interval of over 200 years) affect the whole city including the historic centre. Flood risk in the study area is estimated in EUR 55 million a $^{-1}$ when only direct tangible losses to buildings, household contents and commercial activities are taken into account (Arrighi et al., 2016). In this context, analysis of flood risk to the WSS is crucial to understand the potential adverse consequences on such strategic infrastructures and to estimate the recovery costs.
The metre-scale DTM used for the hydraulic model is freely available in the regional cartographic repository (dati.toscana.it/dataset/lidar). The hydraulic data (hydrographs and river water profiles) are made available by the catchment authority (Autorità di Bacino del Fiume Arno), which is in charge of flood risk management and water resource planning.

Four flood scenarios with different recurrence intervals (RIs) are considered when applying the method described in Sect. 2: a frequent scenario (RI $=30$ years), two medium recurrence intervals (100 and 200 years) and a rare scenario (500 years). Accordingly, four inundation raster maps are generated to carry out the exposure analysis.

\subsection{Water distribution system}

The studied WSS features one main treatment facility, 17 tanks and the pipework to supply drinking water for domestic and industrial use.

Freshwater supply is ensured by the river, which flows westbound amidst the urban area. Water is abstracted from the river by three $373 \mathrm{~kW}$ pumps in the treatment plant "Anconella", which is located in the left bank and designed to process $4 \mathrm{~m}^{3} \mathrm{~s}^{-1}$ (Fig. 3). The water undergoes treatment and reaches the lifting station, where six $710 \mathrm{~kW}$ pumps ensure a maximum head of $60 \mathrm{~m}$ and feed the distribution network. The storage tanks are mostly located at high altitudes and feature a total operative volume of $48620 \mathrm{~m}^{3}$.

An EPANET model of the WSS is provided by the utility operator Publiacqua SpA. The model is barely skeletonised 
and consists of 4863 nodes and 12436 pipes for a total length of the modelled piping network of $619 \mathrm{~km}$.

The WSS elements most vulnerable to floods are the lifting stations and the pumps feeding the storage tanks, because they rely on electrical power and are affected by power outage. Water depth at the location of vulnerable WDS components is compared to a threshold depth to define the operation state of each of them. In this work, a threshold of $0.5 \mathrm{~m}$ is defined, so components experiencing greater depths are considered failed and switched off in the water distribution model. The $0.5 \mathrm{~m}$ threshold has been identified based on the judgement of experts who undertook a "what-if" analysis to evaluate the vulnerability of active components. This threshold has been considered conservative with respect to the mean position of electric and electronic devices observed in the plants.

\section{Results}

In this section, results of the analyses are shown. The section is divided into three subsections. Firstly, flood hazard scenarios are illustrated and the exposure analysis of the WSS components is described; two failure scenarios with different residual functionality of the exposed lifting station are selected (Sect. 4.1). Secondly, the dynamics of the WDN are described, namely the temporal evolution of pressure at nodes and volume in the tanks; population not served, $P_{\mathrm{NS}}$, and contaminated pipe length, $L$, measures are shown for the two failure scenarios (Sect. 4.2). Finally, the results of a sensitivity analysis of the WDN with respect to tank levels are presented (Sect. 4.3), since the role of the tank levels is crucial to satisfying demand during the transient after power outage.

\subsection{Flood and failure scenarios}

Figure 3 shows the results of hazard analysis. For the 30year RI an area of $2.5 \mathrm{~km}^{2}$ is flooded, with an average water depth of $1 \mathrm{~m}$. Two areas are affected, one upstream of the historic city on the right bank (right-hand side of Fig. 3) and one downstream on the left bank (left-hand side of Fig. 3. In the upstream area flood depth is about $0.3 \mathrm{~m}$, whereas in the downstream area water depth locally attains $4 \mathrm{~m}$ in correspondence of excavation zones. For the 100-year RI, the flooded area increases to $12.7 \mathrm{~km}^{2}$ with an average flood depth of about $1 \mathrm{~m}$. In the downstream area, the right bank is also inundated with depth up to $2.5 \mathrm{~m}$. For higher RI (200 and 500 years), the affected areas rise to 20 and $27 \mathrm{~km}^{2}$ and average depths to 1.2 and $1.7 \mathrm{~m}$, respectively. In these scenarios the historic district is also affected (centre of Fig. 3) with water depth as high as $4 \mathrm{~m}$. In the downstream areas water depth locally exceeds $4 \mathrm{~m}$ (see Fig. 4 for an example of 500-year RI inundation).
Table 2. Summary of exposed components.

\begin{tabular}{lrrr}
\hline $\begin{array}{l}\text { Recurrence } \\
\text { interval } \\
\text { (years) }\end{array}$ & $\begin{array}{r}\text { Inundated } \\
\text { area } \\
\left(\mathrm{km}^{2}\right)\end{array}$ & $\begin{array}{r}\text { Depth at } \\
\text { lifting } \\
\text { station } \\
(\mathrm{m})\end{array}$ & $\begin{array}{r}\text { Depth at } \\
\text { VCMantigna } \\
(\mathrm{m})\end{array}$ \\
\hline 30 & 2.5 & 0 & 0 \\
100 & 12.7 & 0.85 & 0.15 \\
200 & 20.5 & 0.90 & 0.73 \\
500 & 27.8 & 1.50 & 2.00 \\
\hline
\end{tabular}

Table 2 shows the results of the exposure analysis. For $\mathrm{RI}=30$ years, none of the vulnerable WSS components is affected. For RI = 100 years, the tank labelled "VCMantigna" is exposed to flood, yet the average flood depth in a buffer zone of $25 \mathrm{~m}$ radius is about $0.15 \mathrm{~m}$, and therefore the electrical devices are assumed in operation. For RI $=200$ and 500 years, the drinking water treatment plant (DWTP) in Anconella, shown in the right-hand side of Fig. 3, is flooded with a water depth exceeding $0.85 \mathrm{~m}$. In these scenarios, issues are expected because of drinking water treatment restrictions, loss of control and power shutdown of the lifting station. The VCMantigna tank is still exposed, with water depths as high as $2 \mathrm{~m}$ for $\mathrm{RI}=500$ years.

\subsection{WDN dynamics and impact metrics}

Results are shown relative to the 200- and 500-year recurrence intervals, those for which failure of the DWTP is expected. In particular, two scenarios are considered: in scenario 1 , it is assumed that the DWTP completely stops providing freshwater to the system; in scenario 2, some backup system is assumed to keep one of the three main pumps feeding the network in operation.

The nodal heads $120 \mathrm{~min}$ after the lifting station failure are shown in Fig. 4 for failure scenarios 1 (Fig. 4a) and 2 (Fig. 4b). At $120 \mathrm{~min}$ after the shutdown in the failure scenario 1 (Fig. 4a), about $50 \%$ of nodes already experience heads lower that $1 \mathrm{~m}$, where just three zones, one in the westernmost part of the network (due to the lower altitude favouring piezometric head) and two on the northern and southern hills (due to local tanks providing capacity; see Sect. 4.3), feature heads higher than $20 \mathrm{~m}$. After $6 \mathrm{~h}$ (Fig. 5), the number of served nodes is further reduced, with only the westernmost part of the network and southern hills (low altitude and higher with a great number of tanks, respectively) being served. For what concerns failure scenario 2 (Fig. 4b), most nodes of the network are operational after $120 \mathrm{~min}$ from the shutdown, with pressures in the minimum range of residual level of service $(1-10 \mathrm{~m})$. A few nodes on the northern hills (about $15 \%$ ) experience heads lower than $1 \mathrm{~m}$ and a significant part of the western city on the right bank experiences heads between 10 and $200 \mathrm{~m}$ due to its low elevation. In both cases the service disruption due to insufficient head also af- 


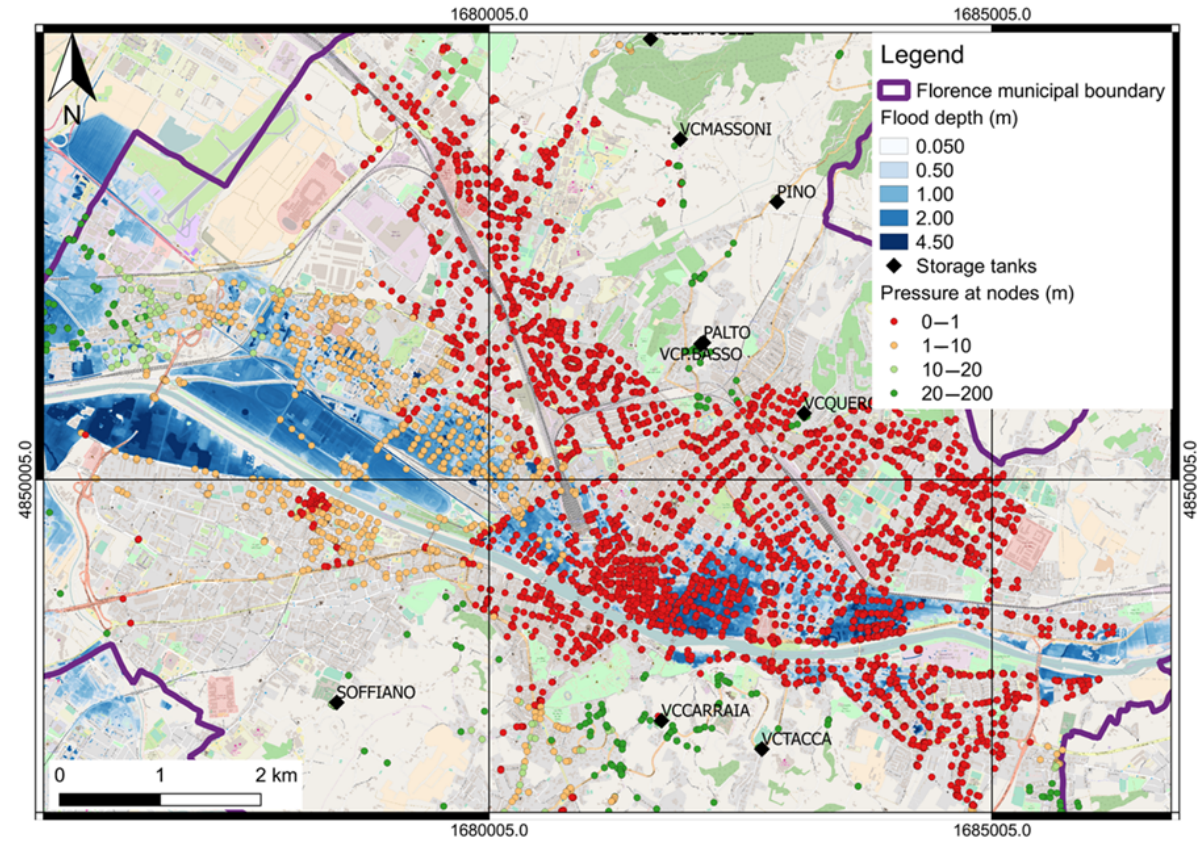

(a)

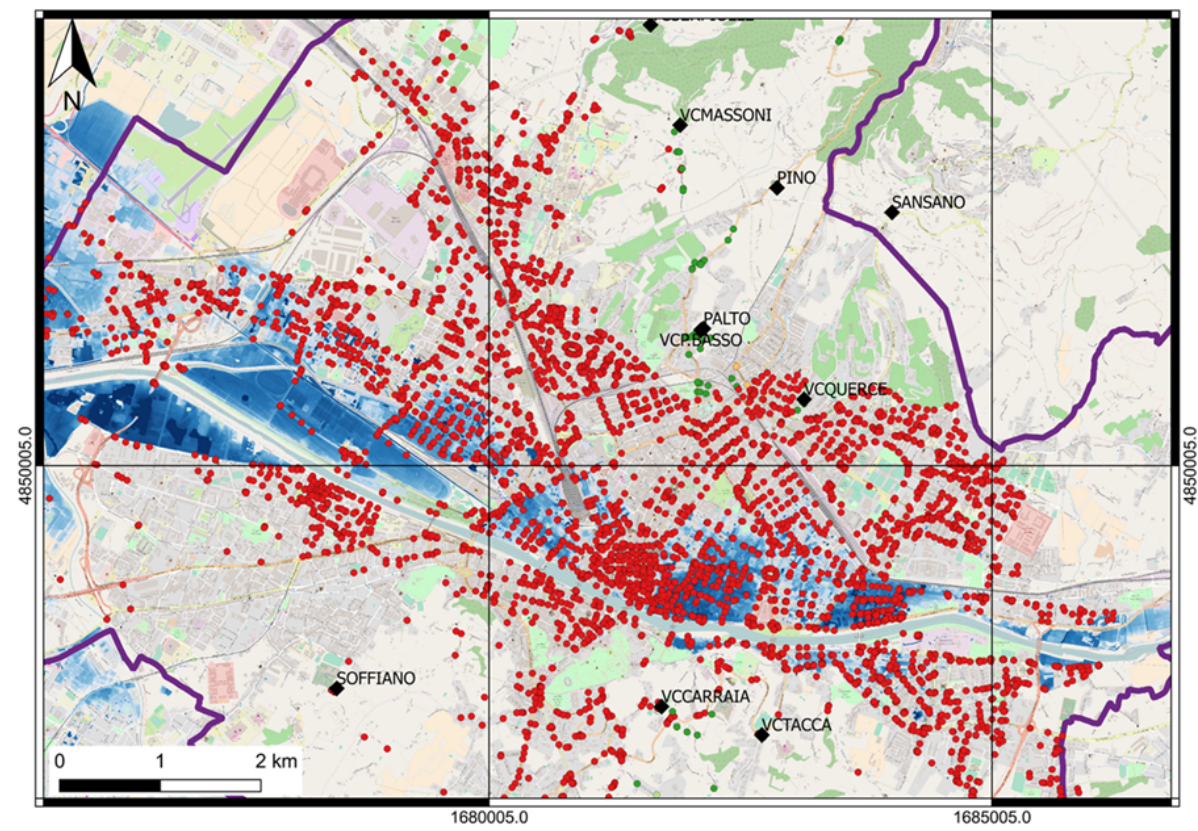

(b)

Figure 4. Inundation map and nodal heads for the 500-year recurrence interval, 120 min after lifting station failure, for (a) scenario 1 (no pumps on) and (b) scenario 2 (one pump on). Reference coordinate system is EPSG:WGS84.

fects nodes outside the inundated area, and hence it can be accounted for as an indirect impact of the flood triggered by the failure of the lifting station.

Evolution of aggregate service metrics in time is calculated for the two aforementioned failure scenarios. $P_{\mathrm{NS}}$ is shown in the panels of Fig. 5 as a fraction of total popula- tion. In failure scenario 1 (Fig. 5a), the complete shutdown of the DWTP pumping station deprives almost $50 \%$ of the population of water supply after $3 \mathrm{~h}$, consistent with the dynamics shown in Sect. 4.2. After 6h, this condition extends to the $70 \%$. If inhabitants experiencing insufficient pressure are also considered, total affected population is about $90 \%$. In 


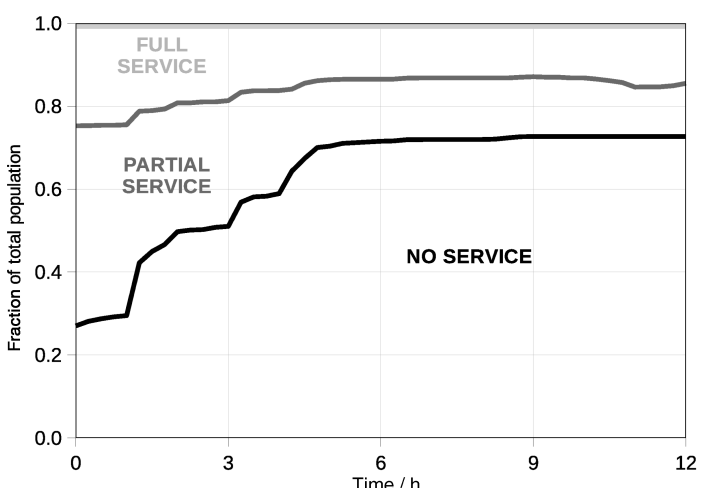

(a)

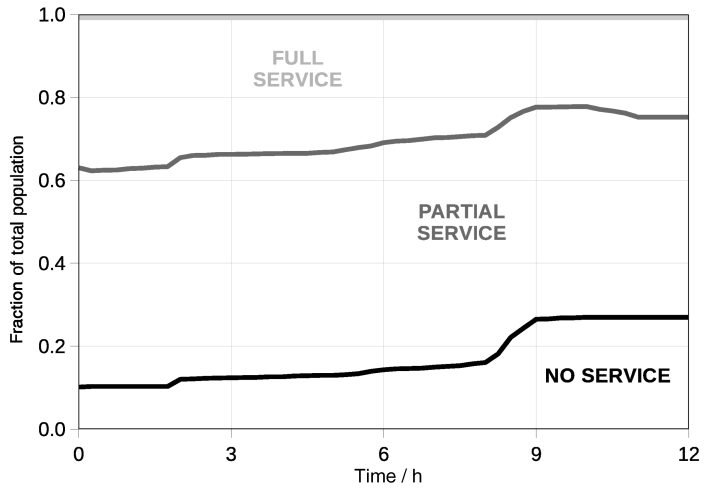

(b)

Figure 5. $P_{\mathrm{NS}}$ as a fraction of total population in failure scenario 1 (a) and failure scenario 2 (b).

failure scenario 2 (Fig. 5b), total affected population ranges from 62 to $77 \%$. Nevertheless, inhabitants experiencing no service at all are about $15 \%$, rising to less than $30 \%$ only after $9 \mathrm{~h}$. Population not served by the WDN exemplifies the large gap between direct and indirect flood impacts. In fact, for the 200- and 500-year flood scenarios, residents directly affected only account for 35.6 and $44.8 \%$ of total population, respectively. This means that inhabitants indirectly affected (by the WSS failure) are two to three times as much as those directly flooded. For what concerns evaluation of network damage, the panels of Fig. 6 show the length of contaminated pipe as a function of time for the two studied failure scenarios. Again, scenario 1 (Fig. 6a) shows a critical situation, where about $25 \%$ of the network undergoes contamination risk shortly after the shutdown and $68 \%$ of the network is out of service just $6 \mathrm{~h}$ afterwards. In scenario 2 (Fig. 6b), the contaminated pipe length fraction rises from 9 to $26 \%$ in the first $12 \mathrm{~h}$, thus suggesting a milder impact. Nevertheless, caution must be taken for the risk of backflow towards nodes which lie on the borders of the served areas. In principle, contaminated pipe length does depend of the RI considered, since higher floodwater depth leads to higher contamination risk. Nevertheless, results show that in the studied case there

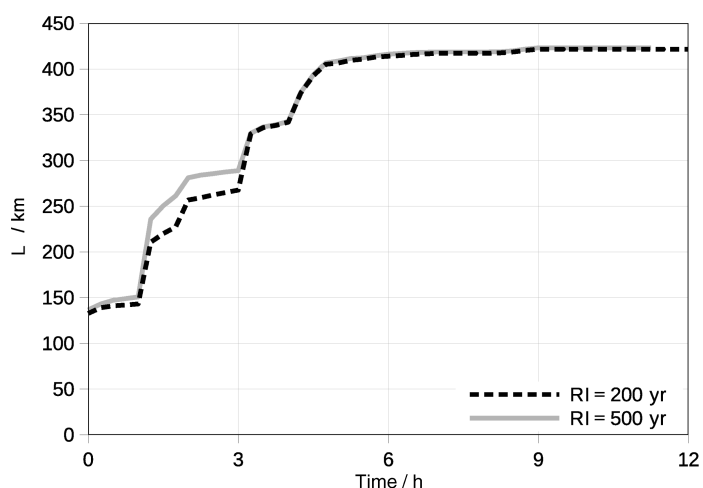

(a)

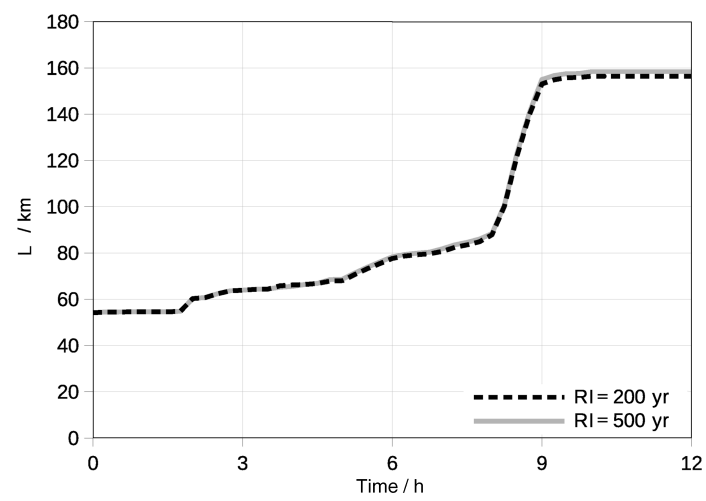

(b)

Figure 6. Contaminated pipe length in failure scenario 1 (a) and in failure scenario 2 (b).

is little difference between the 200- and 500-year recurrence intervals.

If a pipe has been contaminated it needs to be disinfected before being put in service again. Disinfection is usually achieved by flushing: trailer-mounted equipment pumps a disinfecting solution (e.g. liquid chlorine or sodium hypochlorite) through a closed piping loop. Firstly, service laterals are closed and customers are connected to bypass piping. Subsequently, the cleaning solution is pumped from a tank on the equipment trailer into the pipe to be cleaned. After cleaning, the solution is neutralised and pumped to a sanitary sewer. The entire system is then flushed (including laterals) to eliminate sediments and completely remove the disinfecting fluid. From the operational point of view, discharge is monitored during the flushing to assure a sufficient contact time and chlorine residuals after disinfection are recorded to meet the sanitary standards. An order-of-magnitude estimation of the cost of the disinfection-flushing operation is EUR 50 per metre of cleaned pipe (Ellison et al., 2003); nevertheless, during contingencies, costs may increase due to the disproportion between available and needed resources. According to calculated values of contaminated pipe length, flood damage to the WDN can be estimated in EUR 21 and 8 million for failure scenarios 1 and 2, respectively, which correspond to approximately 0.5 and $0.2 \%$ of the direct 


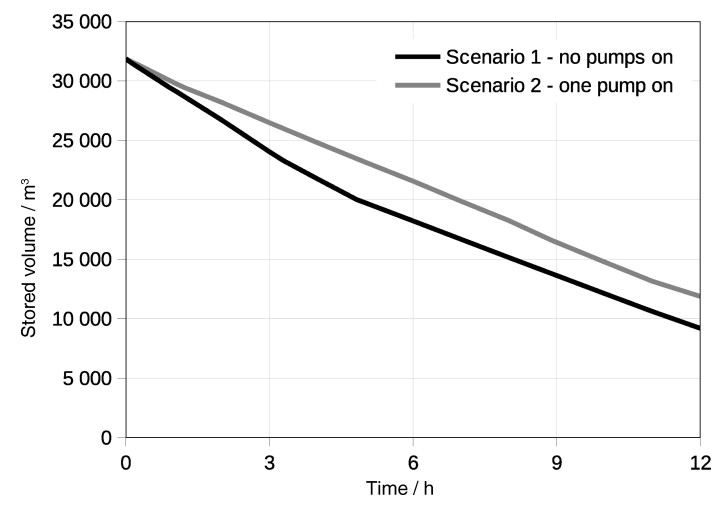

Figure 7. Volume stored in tanks as a function of time since failure.

losses to buildings and contents for the 200-year flood scenario estimated in Arrighi et al. (2016).

Figure 7 shows the water volume stored in the tank system at a given time after the failure. In scenario 1 , where no water is provided by the DWTP, the entire demand is met by withdrawing water from the tank system. This is highlighted by the average slope of the curve in the first $3 \mathrm{~h}$ (about $0.75 \mathrm{~m}^{3} \mathrm{~s}^{-1}$ ), which corresponds to half of the total demand in normal conditions. After about 3 and $5 \mathrm{~h}$, reservoir configuration changes so that the average slope of the volume of the tanks is also affected. Slope changes in both curves are caused both by demand variations and tanks being drained. In particular, the abrupt change for failure scenario 1 after about $5 \mathrm{~h}$ corresponds to a tank serving a great number of nodes being drained, thus corresponding in sudden change in served demand (slope). The relationship between served demand and curve slope is not so evident for failure scenario 2 , since slope curve only relates to those users not directly served by the DWTP.

\subsection{Sensitivity to tank levels}

In case of power shutdown, the transient behaviour of the system is determined by the amount of water stored in tanks. In order to better understand the relevance of each storage tank in the system, a sensitivity analysis has been performed. In particular, a sensitivity matrix is calculated by numerically computing the derivative of head of each node with respect on the level of each tank in a quasi-static assumption. By examining the resulting data, two types of tanks are identified, according to their altitude. On the one hand, variations of water levels in low-altitude tanks strongly impact most network nodes, as shown in Fig. 8a, where the sensitivity to the VCMantigna storage tank is depicted. The nodes of the network lying at elevations in the range $25-50 \mathrm{~m}$ - which largely outnumber the rest - undergo pressure variations of about $0.5-1 \mathrm{~m}$ for a $1 \mathrm{~m}$ variation of tank level. On the other hand, high-altitude tanks, like the one labelled "Arcetri" shown in Fig. 8b, have a smaller area of influence limited to the immediate surroundings of the tank itself. This is also reflected by the longer service periods experienced by nodes pertaining to this areas, which share a locally abundant resource.

\section{Conclusions}

The impact of extreme weather events and natural disasters on urban structures and technological infrastructures, as well as in the perspective of climate change, is causing rising interest of citizens and institutions. In particular, the estimation of damage to network infrastructures poses an additional challenge due to the highly connected physical and functional topology by which the detrimental effects spread to areas farther from the event location and lead to indirect losses.

In this work, a comprehensive methodology to assess the impact of a flood on a WSS is defined and implemented in a semi-automated fashion. In particular, two main submodels are used: (i) an inundation model, which uses hydrometeorological data and a DTM to compute flood depth given the flood recurrence interval (hazard analysis); and (ii) a WSS hydraulic model, used to simulate fluid-dynamic behaviour of the network from topology, functional and demand data. Initially, a flood scenario is calculated by the inundation model, and water depths near the active WSS components (pumps, electrically operated valve, etc.) are extracted. The failure of active components is linked to a selected safety threshold for flood depth, here assumed equal to $0.5 \mathrm{~m}$. If water depth near an active component exceeds the given safety threshold, the component is considered failed (exposure analysis) and its state is modified accordingly in the WSS model. Thereafter, the WSS model is run and nodal pressures are calculated. In this phase, users experiencing lack of service are identified as a function of time. Moreover, by comparing water pressure in the network with local flood depth, areas affected by backflow are identified. Finally, calculated data are aggregated to compute two time-dependent measures which quantify the global lack of service (through the number of affected users) and global contamination extent (through the total length of pipes undergoing backflow).

The described method is applied to a case study. The study area hosts about 380000 inhabitants on an area of $102 \mathrm{~km}^{2}$. The domestic water need (about $121000 \mathrm{~m}^{3} \mathrm{day}^{-1}$ ) is met by a WSS which abstracts the resource from the Arno River, which flows through the town. It is found that flood events with a recurrence intervals greater or equal to 100 years are those which affect functionality and safety of the WSS by causing power disruption to the main lifting station. Two failure scenarios are defined and analysed, considering zero or one pump in operation, respectively. Inundation maps of the area and service maps of the WDN are produced, thus identifying the most critical zones and the service disruption patterns in the two scenarios. Results show that providing a backup system to keep one of the pump in operation would largely reduce the affected population (by about $40 \%$ ). As regards as the contamination of the pipework by floodwater, 


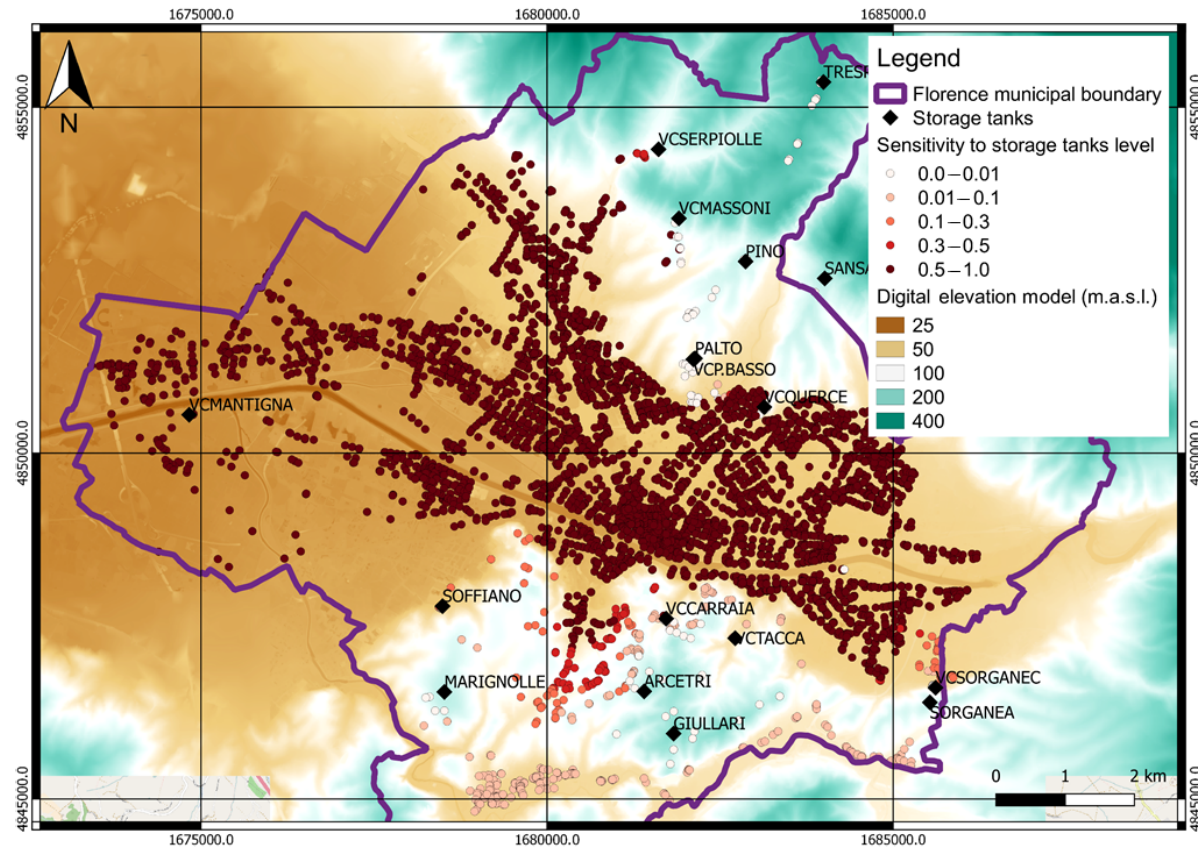

(a)

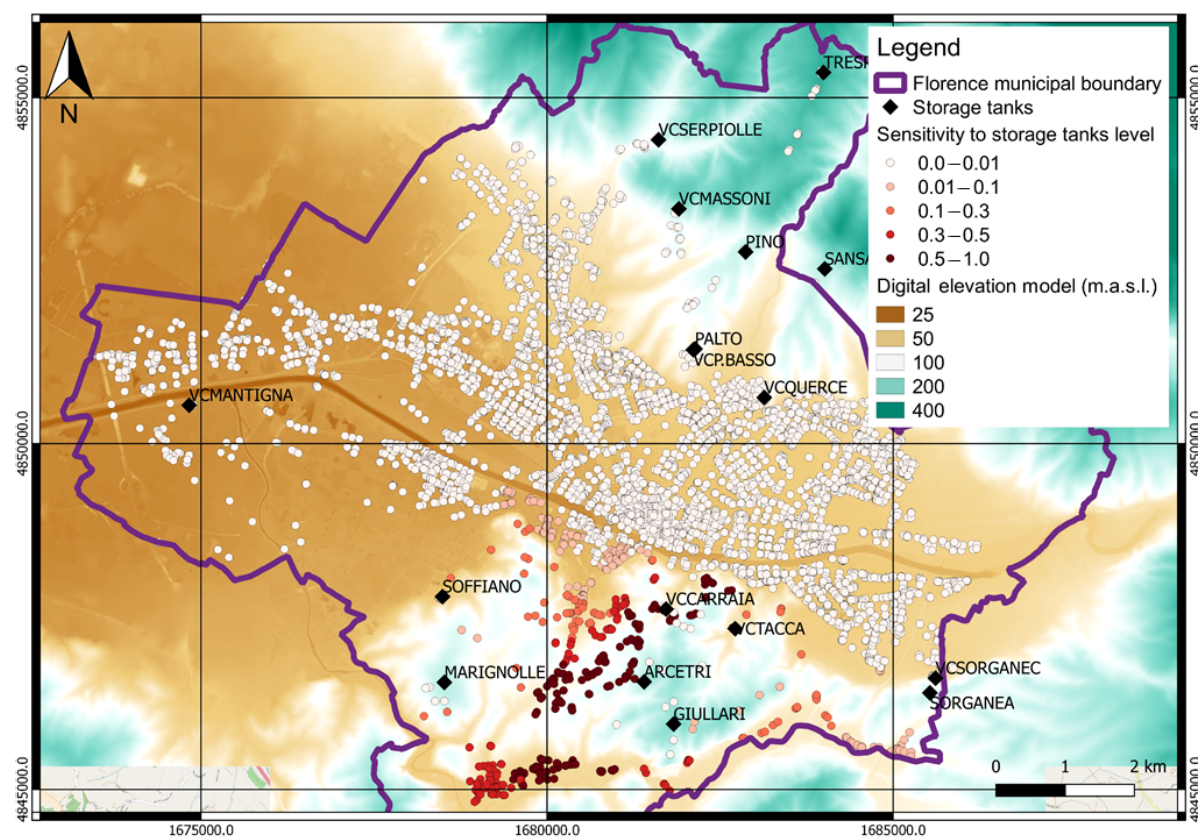

(b)

Figure 8. Digital elevation model of the study area and sensitivity to tank level for a lower tank (VCMantigna) (a) and for a upper tank (Arcetri) (b). Reference coordinate system is EPSG:3003.

in the worst-case scenario it is estimated that 68 to $100 \%$ of the network undergoes backflow risk depending on event duration, whereas the aforementioned improvement would reduce this value by $60 \%$, with first-estimate savings of about EUR 13 million. Sensitivity of nodal head to tank levels is also studied, thus identifying influence areas of the various storage facilities. Although economic losses to the WDN, i.e. the cost of cleaning the pipework, are almost negligible with respect to the direct losses to buildings, their contents and artworks estimated in a previous work (Arrighi et al., 
2016), the calculation of the impact on population reveals that for a 200-year flood and worst failure scenario there are three times as many inhabitants experiencing a lack of freshwater than those directly flooded. This also has crucial implications on the post-emergency management and civil protection actions since interventions are also required outside the inundated area.

The implemented methodology uses flood data (WSS topology and characteristics) and water demand data to compute WSS contamination risk maps and service maps at various time moments after the event. The model is automated and lightweight, the analysis being completed in few minutes, and can be effectively used in the strategic planning of disaster recovery procedures or in comparing network strengthening solutions in budget allocation activities.
Future developments may include studying the effect of first-intervention procedures (e.g. subzoning of the network to select specific areas to be contaminated while preserving operation in others) and extending the model to simulate recovery procedures so that recovery times and transient network behaviour can be estimated based on scheduling and available resources.

Data availability. The data underlying the research are available as a Supplement (*.csv files). 
Appendix A: Acronyms used in the paper

\begin{tabular}{ll}
\hline Acronym & Definition \\
DTM & Digital terrain model \\
DWTP & Domestic water treatment plant \\
Lidar & Light detection and ranging \\
PDD & Pressure-driven demand \\
RI & Recurrence interval \\
WDN & Water distribution network \\
WSS & Water supply system \\
\hline
\end{tabular}




\section{The Supplement related to this article is available online at https://doi.org/10.5194/nhess-17-2109-2017- supplement.}

Author contributions. CA conceived the impact assessment methodology and was responsible of flood hazard, exposure assessment, GIS operations and mapping. FT implemented the PDD code, simulated the piping network and evaluated the impact metrics. EV supervised the network modelling and FC promoted the research and supervised the flood risk aspects.

Competing interests. The authors declare that they have no conflict of interest.

Acknowledgements. We acknowledge Publiacqua SpA for providing the sample network data and for the advice given as stakeholder.

This research was financially supported by Fondazione Ente Cassa di Risparmio di Firenze under the research programme "ECRFI 2014".

Edited by: Bruno Merz

Reviewed by: two anonymous referees

\section{References}

Apel, H., Aronica, G. T., Kreibich, H., and Thieken, A. H.: Flood risk analyses - How detailed do we need to be?, Nat. Hazards, 49, 79-98, https://doi.org/10.1007/s11069-008-9277-8, 2009.

Arrighi, C., Brugioni, M., Castelli, F., Franceschini, S., and Mazzanti, B.: Urban micro-scale flood risk estimation with parsimonious hydraulic modelling and census data, Nat. Hazards Earth Syst. Sci., 13, 1375-1391, https://doi.org/10.5194/nhess13-1375-2013, 2013.

Arrighi, C., Brugioni, M., Castelli, F., Franceschini, S., and Mazzanti, B.: Flood risk assessment in art cities: The exemplary case of Florence (Italy), J. Flood Risk Manage., https://doi.org/10.1111/jfr3.12226, in press, 2016.

Ashley, S. T. and Ashley, W. S.: Flood fatalities in the United States, J. Appl. Meteorol. Clim., 47, 805-818, https://doi.org/10.1175/2007JAMC1611.1, 2008.

Bartram, J., Corrales, L., Davison, A., Deere, D., Drury, D., Gordon, B., Howard, G., Rinehold, A., and Stevens, M.: Water Safety Plan Manual: Step-by-step risk management for drinkingwater suppliers, World Health Organization, Geneva, p. 108, https://doi.org/10.1111/j.1752-1688.1970.tb00528.x, 2009.

Blackmore, J. M. and Plant, R. A. J.: Risk and Resilience to Enhance Sustainability with Application to Urban Water Systems, J. Water Resour. Pl. Manage., 134, 224-233, https://doi.org/10.1061/(ASCE)0733-9496(2008)134:3(224), 2008.

Caporali, E., Rinaldi, M., and Casagli, N.: The Arno River floods, Giornale di Geologia Applicata, 1, 177-192, https://doi.org/10.1474/GGA.2005-01.0-18.0018, 2005.
Cheung, P., Van Zyl, J., and Reis, L.: Extension of EPANET for pressure driven demand modeling in water distribution system, Comput. Control Water Indust., 1, 311-316, 2005.

Christodoulou, S. E.: Water Resources Conservancy and Risk Reduction Under Climatic Instability, Water Resour. Manage., 25, 1059-1062, https://doi.org/10.1007/s11269-010-9770-1, 2011.

Cruz, A. M., Steinberg, L. J., Vetere Arellano, A. L., Nordvik, J.-P., and Pisano, F.: State of the Art in Natech Risk Management, European Commission, Joint Research Centre technical report, 66 pp., available at: http://www.unisdr.org/ files/2631_FinalNatechStateofthe20Artcorrected.pdf (last access: 4 May 2017), 2004.

de Moel, H., van Alphen, J., and Aerts, J. C. J. H.: Flood maps in Europe - methods, availability and use, Nat. Hazards Earth Syst. Sci., 9, 289-301, https://doi.org/10.5194/nhess-9289-2009, 2009.

Ebacher, G., Besner, M.-C., and Prevost, M.: Negative Pressure Events in Water Distribution Systems: Public Health Risk Assessment Based on Transient Analysis Outputs (ASCE), ASCE, Published in Water Distribution Systems Analysis 2010, 471483, https://doi.org/10.1061/41203(425)45, 2010.

Ellison, D., Duranceau, P., Ancel, S., Deagle, G., and McCoy, R.: Investigation of pipe cleaning methods, vol. 1, AWWA Research Foundation and American Water Works Association, USA, http: //wwwtest.waterrf.org/PostingReportLibrary/90938.pdf (last access: 4 May 2017), 2003.

Emanuelsson, M. A. E., Mcintyre, N., Hunt, C. F., Mawle, R., Kitson, J., and Voulvoulis, N.: Flood risk assessment for infrastructure networks, J. Flood Risk Manage., 7, 31-41, https://doi.org/10.1111/jfr3.12028, 2014.

EU Parliament: Directive 2007/60/EC, 2007.

Fewtrell, T. J., Duncan, A., Sampson, C. C., Neal, J. C., and Bates, P. D.: Benchmarking urban flood models of varying complexity and scale using high resolution terrestrial LiDAR data, Phys. Chem. Earth, 36, 281-291, https://doi.org/10.1016/j.pce.2010.12.011, 2011.

Gil, J. and Steinbach, P.: From flood risk to indirect flood impact: Evaluation of street network performance for effective management, response and repair, WIT T. Ecol. Environ., 118, 335-344, https://doi.org/10.2495/FRIAR080321, 2008.

Ginandjar, P., Saraswati, L. D., Pangestuti, D. R., Jati, S. P., and Rahfiludin, Z.: Risk Assessment of Drinking Water Supply System in the Tidal Inundation Area of Semarang - Indonesia, Proced. Environ. Sci., 23, 93-98, https://doi.org/10.1016/j.proenv.2015.01.014, 2015.

Göransson, G., Larson, M., and Bendz, D.: Variation in turbidity with precipitation and flow in a regulated river system-river Göta Älv, SW Sweden, Hydrol. Earth Syst. Sci., 17, 2529-2542, https://doi.org/10.5194/hess-17-2529-2013, 2013.

Hrudey, S. E., Hrudey, E. J., and Pollard, S. J. T.: Risk management for assuring safe drinking water, Environ. Int., 32, 948-957, https://doi.org/10.1016/j.envint.2006.06.004, 2006.

Hunter, N., Bates, P., Neelz, S., Pender, G., Villanueva, I., Wright, N., Liang, D., Falconer, R., Lin, B., Waller, S., Crossley, A. J., and Mason, D.: Benchmarking 2D hydraulic models for urban flooding, Proc. Institut. Civ. Eng.: Water Manage., 161, 13-30, https://doi.org/10.1680/wama.2008.161.1.13, 2008.

IPCC: Summary for Policymakers, Climate Change 2013: The Physical Science Basis, in: Contribution of Work- 
ing Group $\mathrm{I}$ to the Fifth Assessment Report of the Intergovernmental Panel on Climate Change, p. 33, https://doi.org/10.1017/CBO9781107415324, 2013.

Khan, S. J., Deere, D., Leusch, F. D. L., Humpage, A., Jenkins, M., and Cunliffe, D.: Extreme weather events: Should drinking water quality management systems adapt to changing risk profiles?, Water Res., 85, 124-136, https://doi.org/10.1016/j.watres.2015.08.018, 2015.

Large, A., Le Gat, Y., Elacachi, S., Renaud, E., and Breysse, D.: Decision support tools: review of risk models in drinking water network asset management, Vulnerability, Uncertainty and risk, in: 2nd International Conference on Vulnerability and Risk Analysis and Management (ICVRAM) and 6th International Symposium on Uncertainty Modelling and Analysis (ISUMA), July 2014, Liverpool, UK, 587-597, 2014.

Lhomme, S., Serre, D., Diab, Y., and Laganier, R.: Analyzing resilience of urban networks: a preliminary step towards more flood resilient cities, Nat. Hazards Earth Syst. Sci., 13, 221-230, https://doi.org/10.5194/nhess-13-221-2013, 2013.

Luh, J., Royster, S., Sebastian, D., Ojomo, E., and Bartram, J.: Expert assessment of the resilience of drinking water and sanitation systems to climate-related hazards, Sci. Total Environ., 592, 334-344, https://doi.org/10.1016/j.scitotenv.2017.03.084, 2017.

Lung, T., Lavalle, C., Hiederer, R., Dosio, A., and Bouwer, L. M.: A multi-hazard regional level impact assessment for Europe combining indicators of climatic and nonclimatic change, Global Environ. Change, 23, 522-536, https://doi.org/10.1016/j.gloenvcha.2012.11.009, 2013.

ISTAT: 15 Censimento della popolazione e delle abitazioni, Tech. rep., http://www.istat.it (last access: 4 May 2017), 2011.

Merz, B., Kreibich, H., Schwarze, R., and Thieken, A.: Review article "assessment of economic flood damage", Nat. Hazards Earth Syst. Sci., 10, 1697-1724, https://doi.org/10.5194/nhess10-1697-2010, 2010.

Meyer, V. and Messner, F.: National flood damage evaluation methods : A review of applied methods in England, the Netherlands, the Czech republic and Germany, FLOODsite Project Report, p. 49, available at: https://www.cepri.net/tl_files/pdf/ meyermesner2005surveyonnationalflooddamageevaluationmethod. pdf (last access: 30 November 2017), 2005.

Meyer, V., Becker, N., Markantonis, V., Schwarze, R., Van Den Bergh, J. C. J. M., Bouwer, L. M., Bubeck, P., Ciavola, P., Genovese, E., Green, C., Hallegatte, S., Kreibich, H., Lequeux, Q., Logar, I., Papyrakis, E., Pfurtscheller, C., Poussin, J., Przyluski, V., Thieken, A. H., and Viavattene, C.: Review article: Assessing the costs of natural hazards-state of the art and knowledge gaps, Nat. Hazards Earth Syst. Sci., 13, 1351-1373, https://doi.org/10.5194/nhess-13-1351-2013, 2013.
Michielsen, A., Kalantari, Z., Lyon, S. W., and Liljegren, E.: Predicting and communicating flood risk of transport infrastructure based on watershed characteristics, J. Environ. Manage., 182, 505-518, https://doi.org/10.1016/j.jenvman.2016.07.051, 2016.

Murshed, M. F., Aslam, Z., Lewis, R., Chow, C., Wang, D., Drikas, M., and van Leeuwen, J.: Changes in the quality of river water before, during and after a major flood event associated with a $\mathrm{La}$ Ni?? a cycle and treatment for drinking purposes, J. Environ. Sci., 26, 1985-1993, https://doi.org/10.1016/j.jes.2014.08.001, 2014.

Serre, D., Lhomme, S., Heilemann, K., Hafskjold, L. S., Tagg, A., Walliman, N., and Diab, Y.: Assessing vulnerability to floods of the built environment - Integrating urban networks and buildings, VRAM 2011 and ISUMA 2011 Conferences, 746-753, https://doi.org/10.1061/41170(400)91, 2011.

Seyoum, A. G. and Tanyimboh, T. T.: Investigation into the Pressure-Driven Extension of the EPANET Hydraulic Simulation Model for Water Distribution Systems, Water Resour. Manage., 30, 5351-5367, https://doi.org/10.1007/s11269-016-14926, 2016.

Short, M. D., Peirson, W. L., Peters, G. M., and Cox, R. J.: Managing adaptation of urban water systems in a changing climate, Water Resour. Manage., 26, 1953-1981, https://doi.org/10.1007/s11269-012-0002-8, 2012.

Smith, D.: 1994 flood damage estimation - A review of urban stagedamage curves and loss function, Water SA, 20, 231-238, 1994.

Thieken, A., Merz, B., Kreibich, H., and Apel, H.: Methods for flood risk assessment: concepts and challenges, International Workshop on Flash Floods in Urban Areas, 112, http://www.rcuwm.org.ir/En/Events/Documents/Workshops/ Articles/8/6.pdf (last access: 4 May 2017), 2006.

US Environmental Protection Agency: Flood Resilience Checklist, p. 6, available at: https://www.epa.gov/sites/production/files/ 2014-07/documents/flood-resilience-checklist.pdf (last access: 30 November 2017), 2014.

Walski, T., Blakley, D., Evans, M., and Whitman, B.: Verifying Pressure Dependent Demand Modeling, Proced. Eng., 186, 364371, https://doi.org/10.1016/j.proeng.2017.03.230, 2017.

WHO: Guidance on Water Supply and Sanitation In Extreme Weather Events, p. 132, http://www. euro.who.int/en/health-topics/environment-and-health/ water-and-sanitation/publications/2011/ guidance-on-water-supply-and-sanitation-in-extreme-weather-events (last access: 4 May 2017), 2011.

World Economic Forum: The Global Risks Report 2017, 12th Edn., Insight Report, World Economic Forum, Geneva, 2017. 